\title{
QUESTÕES ORTOGRÁFICAS NA GAZETA DE LISBOA (1815) E NA GRAMMATICA PHILOSOPHICA DA LINGUA PORTUGUEZA (1822) \\ Sonia Coelho* Susana Fontes**
}

Resumo: No presente artigo, tendo por base um corpus constituído pela Gazeta de Lisboa (1815) e pela Grammatica philosophica da lingua portugueza (1822), duas tipologias textuais distintas, um texto jornalístico e uma gramática, pretendemos refletir sobre algumas questões ortográficas que caracterizaram os inícios do século XIX, uma vez que a leitura dos textos, desde logo, nos permitiu confirmar a existência de uma clara instabilidade ortográfica. Com efeito, propomo-nos analisar alguns exemplos que comprovam precisamente esta inconstância gráfica, particularmente no que respeita ao uso do ditongo [aj] e do $<\mathrm{h}>$.

Palavras-chave: Gazeta de Lisboa (1815). Grammatica philosophica da lingua portugueza (1822). Ortografia.

\section{INTRODUÇÃO}

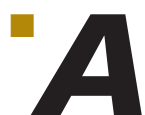

Gazeta de Lisboa surge em 10 de agosto de 1715 com o título de Notícias do Estado do Mundo, sendo apenas nos números seguintes que recebe a denominação Gazeta de Lisboa, publicada ininterruptamente até 1760 , o que faz dela "[...] a publicação periódica portuguesa mais duradoura da primeira metade do século XVIII e, durante muito tempo, a única com carácter noticioso cuja impressão era autorizada" (BELO, 2001, p. 35), assumindo uma importância considerável ao permitir ao leitor português o contacto com o mundo da época.

Esse periódico vai sofrer alterações nos diferentes títulos que apresenta ao longo da sua história. Para além da designação de Gazeta de Lisboa, adotou

\footnotetext{
* Universidade de Trás-os-Montes e Alto Douro (Utad) - Vila Real - Portugal. E-mail: ccoelho@utad.pt

** Universidade de Trás-os-Montes e Alto Douro (Utad) - Vila Real - Portugal. E-mail: sfontes@utad.pt
} 
ainda os títulos de Gazeta de Lisboa Ocidental, Diário do Governo, Diário da Regência, Crónica Constitucional de Lisboa, Gazeta Oficial do Governo, Gazeta do Governo, Diário de Lisboa (cf. TENGARRINHA, 1989, p. 265-266).

Essa publicação começa por ser semanal, no entanto, no século XIX, um contexto político agitado, marcado pelas invasões francesas, exigia intervalos ainda mais curtos entre as publicações, de forma a satisfazer a curiosidade crescente do público, sendo em 1809 que a Gazeta de Lisboa adquire a periodicidade diária.

Em 1822, foi publicada, pela Academia das Ciências, a Grammatica philosophica da lingua portugueza, ou Principios da grammatica geral applicados á nossa linguagem, obra póstuma da autoria de Jerónimo Soares Barbosa ${ }^{1}$, por largo tempo esquecida e incompreendida.

O seu autor foi um homem afinado com o seu tempo e, como profundo conhecedor das letras, representa o expoente máximo da influência das luzes na gramática em Portugal. Na Introdução à obra mencionada, traçando um percurso da gramática, desde as suas origens até ao momento em que escreve, Soares Barbosa censura as gramáticas que aplicam servilmente o modelo latino, sem atenderem às características das linguas vulgares e aplaude aqueles que rompem com as amarras da tradição.

Essa obra teve, durante o século XIX, sete edições (1822, 1830, 1862, 1866, $1871,1875,1881)$, todas elas publicadas sob a chancela da Academia das Ciências de Lisboa.

No presente trabalho, recorrendo à primeira edição da Grammatica philosophica da lingua portugueza, de 1822, e à Gazeta de Lisboa, de $1815^{2}$, dois textos coetâneos e de tipologias distintas, é nosso intento analisar e discutir alguns aspetos ortográficos que caracterizam os textos, verificando semelhanças e dissemelhanças entre eles. Nesta análise, a partir da qual nos será permitido concluir acerca de alguns aspetos que caracterizavam a ortografia no início do século XIX, socorrer-nos-emos da visão de Jerónimo Soares Barbosa, que dedica o II livro da sua gramática à ortografia, e de alguns ortógrafos da época, principalmente de João de Morais Madureira Feijó (1734), autor da Orthographia, ou arte de escrever, e pronunciar com acerto a lingua portugueza ${ }^{3}$, obra que maior influência teve no ideário ortográfico deste período.

Os aspetos que nos propusemos tratar exemplificam casos de instabilidade ortográfica, para os quais não havia uma solução única e consensual, de que são exemplos os ditongos, nomeadamente o ditongo [aj], que será o objeto da nossa análise, e a utilização do $<\mathrm{h}>$.

\section{Ditongo [AJ]}

No que se refere ao ditongo [aj], João de Morais Madureira Feijó contempla duas grafias possiveis, <ay, ai>, que são visíveis nos exemplos que ele usa (pay, pays, dais, mais) e que podem ser considerados como variantes do mesmo ditongo [aj]. Nesse contexto, o autor questiona-se em relação à necessidade da

\footnotetext{
1 Filho de Manuel Freire de S. Lázaro e de Violante Rosa Soares, Jerónimo Soares Barbosa nasceu em Ansião, em finais de janeiro de 1737, e faleceu a 5 de janeiro de 1816, em São João de Almedina, Coimbra.

2 A partir deste momento, passaremos a designar essas obras pelas suas iniciais: GPLP e GL.

3 No nosso trabalho, usaremos a terceira edição, de 1781, por se tratar da primeira edição póstuma, a partir da qual se registaram as principais alterações.
} 
existência de duas grafias para a semivogal anterior: "Pois se o $I$ vogal formado em dithongo com as outras vogaes, tem o mesmo som que o $Y$, com que necessidade se introduz esta letra [...]" (FEIJÓ, 1781, p. 99). Apesar dessa reflexão, Feijó (1781, p. 99) acaba por aceitar a utilização do <y> em determinadas situações, quando assume que "[...] naõ he superfluo entre nós o Y". Por isso, usa o $<y>$ quando a semivogal está em posição intervocálica (cayado, payo, veyo) e quando a grafia está consagrada pelo uso em palavras como rey, ley, pay, boy. Por último, não deixa de enumerar as várias palavras que se escrevem com $<\mathrm{y}>$ devido à sua origem greco-latina, de que são exemplos syllaba, metaphysica, hyperbole. Em relação às palavras grafadas com <i>, Feijó menciona as formas verbais que terminam em ditongo e as palavras portuguesas (foi, amarei, ensinarei, muito, carniceiro), excetuando-se alguns apelidos que, pelo uso, se escrevem com $<\mathrm{y}>$, como Almeyda, Teixeyra, Correya.

No caso do ditongo <ae>, revelando a falta de destrinça entre ditongos orais e nasais, verificamos que os seus exemplos (caẽs, paẽs) remetem para o ditongo

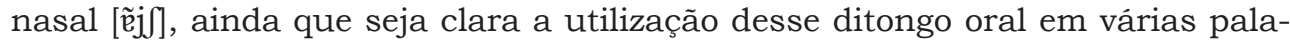
vras do seu texto, de que é exemplo o plural do nome vogal: vogaes.

No que respeita à representação do ditongo [aj], Jerónimo Soares Barbosa (1822, p. 16) apresenta, na taboa dos ditongos, três possibilidades de realização gráfica: <ai, ay, ae>. Relativamente à segunda das grafias, <ay>, apesar de ser contemplada como uma possibilidade para grafar esse ditongo, não é considerada na gramática, até porque o autor entende que se existem carateres nacionais para representar a letra $<y>$, e se a palavra é portuguesa, ela é desnecessária.

$\mathrm{Na}$ Gazeta de Lisboa (1815), e corroborando essas considerações, verificamos que a tendência é para deixar de usar o $\langle\mathrm{y}\rangle$, sendo que no texto, para além do nome bayoneta, figuram apenas topónimos (Bayonna e Hay) e antropónimos (Adelayde e Raymundo).

$\mathrm{Na}$ Grammatica philosophica ${ }^{4}$, apenas temos ocorrências de <ay> na taboa dos ditongos, onde é apresentado o respetivo exemplo, Páy $y^{5}$, e na forma hay, que consiste no acrescento de um $<\mathrm{i}>$ à forma ha, do verbo haver, e se trata de uma manifestação dialetal, segundo o autor própria dos Beirões. Ora essa segunda forma provavelmente surge grafada com $<y>$ por lapso, pois o texto é claro ao referir que é um $<\mathrm{i}>$ que se junta à forma verbal e não um $<\mathrm{y}>$. Ademais, a forma hay só ocorre nas duas primeiras edições; nas restantes já encontramos hai.

Relativamente à grafia <ae>, no corpus surge associada à formação dos plurais das palavras terminadas em <-al>, às quais, "[...] tirada a consoante final, com o accrescentamento do es se fazem pluraes, como: Animál Animáes [...]" (BARBOSA, 1822, p. 136). Essa era uma regra muito comum entre os gramáticos e ortógrafos e pode ler-se, por exemplo, na Orthographia de Feijó (1781, p. 112): “252. Todos os nomes, que no singular acabaõ em al, no plural acabaõ em aes agudo; como Cana, Canâes, Animal Animâes, Fatal Fatâes, Jornal, Jornâes, Casal Casâes, Moral Morâes, Plural Plurâes, etc.”.

4 Nos exemplos que apresentarmos, não consideraremos os casos que surgem inseridos em citações de outros autores, uma vez que frequentemente se trata da ortografia do autor citado e não de Soares Barbosa.

5 Note-se que essa é uma palavra com várias ocorrências no texto e esta é a única vez que ocorre com <y>, o que significa que foi assim registada apenas para ilustrar essa possibilidade gráfica.

6 Segundo Filomena Gonçalves (2003, p. 83), "a grafia histórica <ae>, vinculada ao plural latino em <-ALES>, identifica o plural nominal (Animal-Animaes), constituindo um exemplo de morfograma, vale dizer, uma grafia dotada de função distintiva ao nível morfológico". 
Essa é precisamente a regra seguida nos dois textos, nos quais encontramos sempre a representação <ae> para marcar a regra dos plurais supramencionada. Seguem-se alguns exemplos que nos permitem ilustrar a aplicação dessa regra: hospitaes, iguaes, illegaes, illiberaes, immoraes, immortaes, imparciaes, imperiaes, individuaes, industriaes, infernaes, jornaes, na Gazeta de Lisboa, e especiaes, essenciaes, geraes, graduaes, individuaes, pluraes, quaes, racionaes, na Grammatica philosophica.

A grafia <ae> regista-se também em determinadas formas verbais, nomeadamente nas desinências das terceiras pessoas do singular e plural dos verbos cair e sair e seus compostos, como nos atestam as palavras do padre Caetano de Lima (1736, p. 112), ortógrafo coetâneo de Feijó: "Acha-se nos Verbos Cae, Sae, e nos seus pluraes Caem, Saem, como também nos Compostos dos ditos Verbos Descae, Recae, Sobresae".

Segundo Soares Barbosa (1822, p. 276), era comum que verbos como cair, sair, atrair, contrair, distrair e recair se grafassem com $<\mathrm{h}>$, que tinha precisamente a função de não permitir que as duas vogais em hiato formassem ditongo: "[...] o $h$, com que ora se escrevem, he para separar as duas vogaes em ordem a não fazerem diphthongo [...]”. Assim, esses verbos apresentam a seguinte grafia: attrahir, cahir, contrahir, distrahir, recahir e sahir.

As formas sobre as quais nos interessa debruçar são apenas as relativas às terceiras pessoas, e dessas, nos textos, temos ocorrências dos verbos cair, sair e recair, por exemplo. Comecemos com a terceira pessoa do singular do verbo cair. A representar essa forma, na GL, encontramos apenas cahe, ao passo que, na GPLP, encontramos as seguintes possibilidades: cahe, cáe, cae e cai ${ }^{7}$ o que nos permite concluir a priori que não há uniformidade, sendo, no entanto, a primeira forma inquestionavelmente maioritária.

Quando Soares Barbosa (1822, p. 276) se refere ao uso do $<$ h $>$ nos verbos cair e sair, o autor indica outras possibilidades de grafia, inclusive já usadas por autores antigos, eliminando assim esse grafema: “[...] muito melhor fazião isto nossos antigos dobrando o $i$, e escrevendo Caiir, Saiir; e nós ainda melhor, accentuando o mesmo $i$ deste modo: Cair, Sair, e tirando o accento, quando faz diphthongo [...]". Isso significa que contempla a hipótese da eliminação do $<\mathrm{h}>$ nessas formas, marcando-se o hiato através da acentuação, por exemplo, caía, que é diferente de caia.

Nesse sentido, é natural que as formas desses verbos possam ocorrer sem o $<\mathrm{h}>$. Aliás, é precisamente isso que acontece na GPLP, quando surgem as terceiras pessoas dos verbos sair e recair, que nunca ocorrem com o $<\mathrm{h}>$ : sae, saem $\mathrm{e}$ recae. Contrariamente, na $G L$, essas formas nunca surgem sem o elemento anti-hiático: sahe, sahem e recahe.

Resta-nos a grafia <ai>, que surge em palavras como baixo, caixa, demais, faixa, hebraica, painel, paixão, Embaixador, mosaico, entre outros. Esses vocábulos aparecem grafados sempre dessa forma nos textos em análise.

Podemos também encontrar a representação <ai> nas segundas pessoas do plural do presente do indicativo, do conjuntivo e do imperativo dos verbos, por exemplo, amais, tenhais, pagai, chamais, inspirai, julgai.

7 Essa forma surge num contexto muito específico, no capítulo dedicado às Regras proprias da orthographia da pronunciação, portanto aparece representada tal qual se pronuncia, não sendo, consequentemente, regra. 
Relativamente à terminação <ai> para essas formas verbais, atentemos nas palavras de Madureira Feijó (1781, p. 112), nas quais fica claro a sua opção por esta grafia: "As linguagens dos verbos em ar, como Amar, Ensinar, \&c. na segunda pessoa do plural acabaõ em ais, como Amais, Ensinais, Levais, Usais, \&c. [...] e advirta-se, que estas terminaçoens saõ dithongos", e noutro passo o ortógrafo é ainda mais preciso, dizendo, a propósito das formas verbais amai, ensinai, chorai e fallai, que "[...] estas linguagens dos verbos andaõ na nossa Arte com I vogal; e naõ ha homem douto, que assim naõ escreva" (FEIJÓ, 1781, p. 98).

Jerónimo Soares Barbosa (1822, p. 229), no parágrafo dedicado aos números e pessoas do verbo, indica as terminações adotadas para designar as diferentes pessoas e, quando refere a segunda do plural, diz que esta termina "[...] em ais ou astes, em eis ou des, em is ou des", e, mais à frente, quando faz uma advertência acerca de algumas formas antiquadas, acrescenta o seguinte:

Na primeira Linguagem antiga desde ElRei D. Affonso Henriques até ElRei D. Diniz, e ainda algum tempo depois, erão differentes as terminações das segundas pessoas do plural nestas Linguagens; pois em lugar de i, pospositiva de todos os diphthongos finaes, por que acabão estas segundas pessoas, substituião hum de, como nos versos de Egas Moniz Coelho á sua Dama: Amademe, se queredes, em vez de Amai-me, se quereis (BARBOSA, 1822, p. 253).

Portanto, parece-nos que a leitura desses dois excertos não nos deixa dúvidas quanto às propostas do gramático, que aponta a vogal $<i>$ para representar a semivogal desses ditongos, o que, na verdade, era frequente, sobretudo para os verbos de tema em -a.

Nos textos em análise, a grafia <ai> surge, por exemplo, nas seguintes formas verbais: amai, amais, dai, dais, estai, estais, louvai, louvais, tenhais, vai, vais, pensai, ficais, disfructai, sintais, sejais. No entanto, paralelamente, ainda que num valor muito mais reduzido, encontramos algumas formas com a grafia <ae>: estaes, estejaes, sejaes ${ }^{8}$, hajaes, tenhaes, desejaes, expressaes, façaes, tenhaes, representaes, permittaes, o que denuncia a instabilidade que existia na representação gráfica desse ditongo. Essa confusão entre <ae> e <ai> é constatada, por exemplo, por Lima (1736, p. 113), quando trata do ditongo <ai>.

Seguidamente apresentamos o Quadro 1, no qual sintetizamos os dados dos quais cremos ser possivel chegar a uma regra ${ }^{9}$.

\section{Quadro 1 - Ditongos <ay, ae, ai> na GL e na GPLP}

\begin{tabular}{|l|l|l|l|}
\hline \multicolumn{2}{|c|}{} & GL & GPLP \\
\hline$<$ ay> & $\begin{array}{l}\text { Bayoneta, Adelayde, Ayres, } \\
\text { Raymundo, Jayme, Payva, } \\
\text { Bayona, Hay, Cambray }\end{array}$ & páy \\
\hline
\end{tabular}

(continua)

8 Essa forma é considerada por Feijó (1781, p. 144) um erro do vulgo: "No imperativo: Sejais vós em lugar de Sêde vós". Repare-se ainda que o ortógrafo a grafa com <ai>.

9 Os exemplos apresentados não constituem a listagem completa das ocorrências de palavras com esse ditongo, apenas selecionámos algumas como forma de ilustração.

10 No que respeita a essa palavra, como já salientámos, só apresenta essa ocorrência, certamente com o propósito de exemplificar a grafia <ay>, não sendo portanto, como vimos, a grafia adotada para a palavra pai no texto. 
Quadro 1 - Ditongos <ay, ae, ai> na GL e na GPLP (continuação)

\begin{tabular}{|c|c|c|c|}
\hline & & GL & GPLP \\
\hline \multirow[t]{2}{*}{$<\mathrm{ae}>$} & $\begin{array}{l}\text { Plural das palavras } \\
\text { terminadas em }<- \text { al }>\end{array}$ & $\begin{array}{l}\text { animaes, brutaes, cabedaes, } \\
\text { canaes, Cardeaes, casaes, } \\
\text { castiçaes, coloniaes, } \\
\text { commerciaes, confidenciaes, } \\
\text { constitucionaes, infernaes, } \\
\text { jornaes, paternaes }\end{array}$ & $\begin{array}{l}\text { artificiaes, arraes, especiaes, } \\
\text { essenciaes, geraes, } \\
\text { graduaes, individuaes, } \\
\text { pluraes, quaes, racionaes, } \\
\text { verbaes, verticaes, vogaes }\end{array}$ \\
\hline & $\begin{array}{l}\text { Formas verbais } \\
\text { (residualmente) }\end{array}$ & $\begin{array}{l}\text { desejaes, expressaes, façaes, } \\
\text { tenhaes, representaes, } \\
\text { permittaes }\end{array}$ & $\begin{array}{l}\text { estaes, estejaes, hajaes, } \\
\text { sejaes, tenhaes }\end{array}$ \\
\hline \multirow[b]{2}{*}{$<$ ai $>$} & $\begin{array}{l}\text { Em algumas } \\
\text { palavras, como: }\end{array}$ & $\begin{array}{l}\text { Baile, bairro, Baixo, caixa, } \\
\text { Embaixada, gaivotas, } \\
\text { paixão, praia }\end{array}$ & $\begin{array}{l}\text { baixo, caixa, demais, faixa, } \\
\text { hebraica, painel, paixão }\end{array}$ \\
\hline & Formas verbais & $\begin{array}{l}\text { acreditai, aproveitai, } \\
\text { conservai, contemplai, } \\
\text { Desprezai, gozais, justificai, } \\
\text { observai, sejais }\end{array}$ & $\begin{array}{l}\text { amai, amais, dai, dais, estai, } \\
\text { estais, louvai, louvais, } \\
\text { tenhais, vai, vais }\end{array}$ \\
\hline
\end{tabular}

Fonte: Elaborado pelas autoras.

\section{O USO DO $<\mathrm{H}>^{11}$}

No alfabeto do uso apresentado por Soares Barbosa, não encontramos esse grafema. É só quando o gramático apresenta o abecedário vulgar ou tipográfico que ele surge; no entanto o autor aponta-o como uma letra sobeja, “[...] que, ainda sendo signal de aspiração, não deve ter lugar entre as Consoantes, mas sim entre os Accentos Prosodicos, aonde pertence" (BARBOSA, 1822, p. 59). Ora, como podemos constatar, mantém-se aqui a tradição de atribuir ao $<\mathrm{h}>$ uma função de aspiração.

Efetivamente, no capítulo dedicado às modificações prosódicas, o gramático, para além de indicar os acentos agudo, grave e circunflexo, acrescenta um quarto acento, que corresponde ao espírito áspero dos gregos:

Alêm destes tres Accentos ha outro de Aspiração, que os Gregos notavão ao principio com dois E\}virados hum para outro, ou unidos deste modo $H$, e depois com a figura de huma virgula ás avessas, lançada por cima da vogal; e os Romanos com o primitivo $H$ dos Gregos, posto na mesma linha antes da vogal aspirada (BARBOSA, 1822, p. 41).

Comparando a lingua portuguesa com a castelhana, no caso específico da nossa língua, o autor reconhece que a aspiração é quase inexistente, verificando-se apenas nas interjeições, pois essas palavras caracterizam-se por exprimirem

\footnotetext{
11 A propósito dessa "letra", verificamos que existem propostas muito distintas para a sua utilização. Destacamos, a título exemplificativo, a de Verney, que defendia a supressão total de " $\mathrm{h}$ " em todos os contextos, movido por um princípio fonético, que o separa da maioria dos ortógrafos. Numa tendência conservadora, estes manifestam uma ligação à etimologia e também ao uso, o que os separa da linha radical de Verney.
} 
as paixões da alma e, como tal, são as únicas que registam esta marca própria dos gregos (cf. BARBOSA, 1822, p. 41).

Feijó, na senda dessa antiga tradição, também considera o $<$ h $>$ como sinal de aspiração, acrescentando-lhe ainda as funções distintiva e de letra:

139 Na lingua portugueza necessariamente havemos de dizer, que he letra; porque aquella se deve chamar letra, sem a qual as palavras naĩ ficaó significativas, nem sôaõ como ellas saõ. E quem duvída, que se tirarmos o H ás palavras, que escrevemos com Lha, lhe, lhi, lho, lhu: ou Cha, che, chi, cho, chu: ou Nha, nhe, nhi, nho, nhu, nenhuma se poderá pronunciar, nem ficará significativa; porque Chave sem H fica Cave. Tenho, Teno. Linha, Lina, \&c. Mas tambem ha huma multidaõ de palavras portuguezas, em que usamos do $\mathrm{H}$ só como aspiraçaõ; e em muitas he preciso, para differença de outras, que sem $\mathrm{H}$ se equivocaõ, como E conjunçaõ, e He terceira pessoa do verbo Est no portuguez: Ja, adverbio; $e$ Hia, linguagem do verbo Ir, que he Eo, is; Ibat elle hia, \&c ${ }^{12}$ (FEIJÓ, 1781, p. 68).

$\mathrm{Na}$ sequência das apreciações acerca da função do $<\mathrm{h}>$, Soares Barbosa tece algumas considerações sobre o uso que na nossa lingua se conferia a esse grafema, evidenciando as funções identificadas por Feijó e acrescentando mais uma: integrar os digrafos portugueses $<\mathrm{ch}, \mathrm{lh}, \mathrm{nh}>$ :

Usa porêm frequentemente do H para outros fins; ja para figurar algumas Consonancias suas proprias, que os Romanos não tinhão, quaes são as Prolações $\mathrm{CH}, \mathrm{LH}, \mathrm{NH}$; ja para conservar as etymologias Gregas e Latinas, como em Hypothese, Homem; ja para distinguir os sons semelhantes, como há verbo de á preposição, hi adverbio de i vogal, e hum nome de um vogal nasal (BARBOSA, 1822, p. 41).

Como já dissemos, esse grafema serve para marcar a aspiração, fenómeno que se verifica nas interjeições ${ }^{13}$. Ao contrário do que seria considerado regra num texto jornalístico atual, não compatível com a utilização de interjeições, que permitem exteriorizar determinados estados de espírito, na Gazeta encontramos estes exemplos que aqui deixamos: "Oh bom Deos! [...] Oh loucura da sapiencia do seculo! oh delirio! oh insulto da razão! [...] Oh Providencia!" (GL, n. 97, 26 de abril de 1815: [III]). Na GPLP, temos também alguns exemplos de interjeições, que surgem sempre grafadas com $<\mathrm{h}>$, tal como acontece ainda hoje com algumas delas: ah!, hai!, oh!, ah! ah!, hui!.

Sendo o $<$ h $>$ um carater latino, Soares Barbosa (1822, p. 71) considera que ele deve figurar nas palavras que em latim o continham, de modo a evidenciar a sua etimologia:

Ainda que o H não tenha valor algum entre nós fóra talvez das Interjeições, comtudo deve-se conservar na escriptura das palavras, dirivadas do Latim para mostrarem a sua origem e com ella sua significação primitiva. Pelo que devemos

12 Feijó acrescenta também que em alguns nomes de origem não portuguesa que terminam em $<\mathrm{h}>$ devemos ter em conta a origem da palavra, e por isso, ainda que não haja palavras portuguesas terminadas em $\langle\mathrm{h}\rangle$, ele apresenta alguns topónimos e antropónimos acabados dessa forma, e condena aqueles que propõem a grafia <José> para o nome próprio <Joseph>: “[...] naõ devemos tirar aos nomes proprios indeclinaveis aquella terminaçaõ, com que passáraõ para o nosso uso, porque sem ella naõ ficarám proprios, nem se saberá, que nomes saõ [...]" (FEIJó, 1781, p. 71).

13 "Nas Interjeições ah! oh! hui! ha a razão de serem estas vozes naturalmente aspiradas; para o que he muito proprio o $\mathrm{H}^{\prime \prime}$ (BARBOSA, 1822, p. 71). 
escrever com elle Habil, Habitar, Habito, Haver, Herdar, Historia, Hombro, Honesto, Honra, Horror, Hospede, Homem, Humor, Hora, e outros semelhantes.

Para além das palavras já registadas na citação, nos dois textos, encontramos este $<\mathrm{h}>$ etimológico, em contexto inicial, também nas palavras hoje, homicidas, honestidade, horizontaes e, em contexto medial, nas diferentes formas dos verbos abstrahir, comprehender, contrahir, exhortar, extrahir.

Nos textos estudados, relativamente à função distintiva, encaixam-se as palavras, que, como vimos em Feijó, assim se grafavam para se distinguirem de outras: hum (artigo indefinido ou numeral) de um (vogal nasal); he (verbo) de $e$ (conjunção) ${ }^{14}$; hia (verbo) de ja (advérbio). Segundo o gramático, esses casos são exemplos das incoerências da ortografia usual, que não tem em consideração o fenómeno da derivação (cf. BARBOSA, 1822, p. 57).

Note-se, no entanto, que na $G L$, embora essas formas grafadas com $<\mathrm{h}>$ sejam ainda maioritárias, convivem também os artigos/numerais $u m / u m a$ e a forma verbal îa, já sem o $<\mathrm{h}>$, anunciando uma mudança que viria a concretizar-se. A corroborar esses usos, encontramos as palavras do ortógrafo Carlos Augusto de Figueiredo Vieira (1844, p. 45): "Não deve empregar-se o $h$, onde nem a etymologia nem a pronuncia o reclamam; devemos por tanto escrever sem elle é, um, uma, ia, ias \&c".

No que diz respeito à função anti-hiática do $<\mathrm{h}>$, encontra-se nas palavras cahir, sahir, ahi, bahia, bahú, e serve para evidenciar que as duas vogais em contacto não formam ditongo. Como uma alternativa preferivel a este procedimento, a propósito das formas verbais, Soares Barbosa indica o recurso à acentuação, que retiraria as dúvidas:

Porque, se o h, com que ora se escrevem, he para separar as duas vogaes em ordem a não fazerem diphthongo, e mostrar que o i he longo e agudo; muito melhor fazião isto nossos antigos dobrando o i, e escrevendo Caiir, Saiir; e nós ainda melhor, accentuando o mesmo i deste modo: Caír, Saír; e tirando o accento, quando faz diphthongo no presente do indicativo e do subjunctivo, como Caio, Caia, Saio, Saia, \&c. (BARBOSA, 1822, p. 267).

Nos textos, encontra-se $\mathrm{o}<\mathrm{h}>\mathrm{com}$ a função anti-hiática em palavras como ahi, cahe, cahem, cahir, cahírão, dahi, sahir, sahissem, entre outras. No entanto, na GPLP verificamos que essas formas convivem dentro do mesmo texto com outras já grafadas sem $<$ h $>$, de que são exemplo cae, cair, sae, saem, sair, saindo. $\mathrm{Na} G L$, todas essas formas surgem ainda grafadas com $<\mathrm{h}>$.

Outra função reconhecida ao $<$ h $>$ é como elemento constitutivo dos dígrafos portugueses <ch, lh, nh>, surgindo nos textos em palavras como choque, China, ilha, Guilherme, Junho, tenho, achar, caprichar, chá, coelho, conselho, escolhido, façanhas, ganhar, linha.

A propósito do dígrafo $<\mathrm{nh}>$, deixamos uma advertência para os casos em que encontramos a sequência $\langle\mathrm{n}+\mathrm{h}\rangle$, em interior de palavra, que não representa um grafema. Isso é visivel nas palavras inabilitação, inhabilitão, inhabeis, inherente, inhumano, inhumanamente, anhela, anhelava, anhelando, presentes na GL, e anhomologas, inhabil, na GPLP, resultando da observância do princípio etimológico.

14 A propósito dessas duas últimas formas, Verney $(1746$, p. 23) refere que elas se distinguem facilmente através da acentuação: "O é quando é Verbo, muito bem se-distingue do-e Conjunsam, pondo-lhe emcima um acento. Nem eu poso intender porque razam é Verbo, deva escrever-se com $h$, e era, eram \&c. que sam inflexoens do-mesmo Verbo, sem ele". 
Sistematizemos, de seguida, os dados compulsados acerca dos usos do $<\mathrm{h}>$ nos textos.

Quadro 2 - O uso do $<\mathrm{h}>$ na $G L$ e na GPLP

\begin{tabular}{|l|l|l|}
\hline \multicolumn{2}{|c|}{} & GL e GPLP \\
\hline \multirow{4}{*}{$<\mathrm{h}>$} & Sinal de aspiração & ah!, hai!, oh!, ah! ah!, hui! \\
\cline { 2 - 3 } & Etimológico & $\begin{array}{l}\text { habil, habitar, habito, haver, herdar, historia, hombro, } \\
\text { honesto, honra, horror, hospede, homem, humor, hora, hoje, } \\
\text { honestidade, horizontaes }\end{array}$ \\
\cline { 2 - 3 } & Sinal distintivo & he, hum, hia \\
\cline { 2 - 3 } & Anti-hiático & ahi, cahe, cahem, cahir, cahírão, dahi, sahir, sahissem \\
\cline { 2 - 3 } & $\begin{array}{l}\text { Dígrafos }<\mathrm{ch}, \mathrm{lh}, \\
\text { nh> }\end{array}$ & $\begin{array}{l}\text { achar, caprichar, chá, coelho, conselho, escolhido, façanhas, } \\
\text { ganhar, linha, choque, China, ilha, Guilherme, Junho, tenho }\end{array}$ \\
\hline
\end{tabular}

Fonte: Elaborado pelas autoras.

\section{O uso do <h> nos dígrafos gregos}

O papel do $<$ h> não se esgota, porém, nas funções acima indicadas. Ele é também parte integrante dos dígrafos gregos $<\mathrm{ch}$, ph, th, rh $>$, cujo uso se generalizou com a chegada do Renascimento e consequente aproximação do português às línguas clássicas.

No que respeita ao dígrafo <ch>, Feijó (1781, p. 55) propõe uma solução que combina uso e etimologia:

Em nenhuma palavra portugueza póde haver $\mathrm{C}$ aspirado com $\mathrm{H}$ no som de $\mathrm{Q}$; mas ou haõ de ser tiradas dos latinos, ou dos Gregos; e ou sejaõ de huns, ou de outros, se as traduzimos ao nosso uso, naõ necessitaõ de $\mathrm{H}$ para a sua Orthografia, e pronunciaçaõ portugueza; porque o nosso $\mathrm{C}$ tem a consonancia de $\mathrm{Q}$, antes das vogaes a, o, u, quando se naõ escreve plicado; como v. g. Caro, Corôa, Cura, \&c. Mas se as traduzimos ao uso latino, ou alatinado, sem as extrahir da sua pronunciaçaõ, e significação latina, entaõ precisamente se haõ de escrever como os latinos as escrevem, por naõ fazermos humas palavras, que nem seraõ latinas, nem portuguezas; e por naõ lhes tirarmos as letras, que nos mostraõ a sua origem, para sabermos o que significaõ.

Por seu turno, Soares Barbosa proscreve o uso desse dígrafo e justifica essa opção argumentando que essa prolação já tem uma função na língua portuguesa. Posto isso, não pode ser empregue em representação do $<x>$ sem que se gere equivoco:

Disse na Regra: Que se poderem representar pelos caracteres do nosso Alphabeto: porque algumas não se podem; ou por não termos nelle letra propria para isto, como o K antes de e, e i, que substituimos com a Prolação Latina QU: ou por termos ja preoccupado para alguma das nossas consonancias proprias as Letras que competirião ás Gregas e Latinas, como o $\mathrm{CH}$, que servindo-nos para figurar a nossa chiante muda, como em Chá, ja a não podemos empregar sem equivoco em Archãjo, Architecto \&c. (BARBOSA, 1822, p. 69). 
Essa posição é criticada por Feijó (1781, p. 54), para quem não se justifica eliminar $\mathrm{o}<\mathrm{ch}>$ só porque se pode tornar dúbia a significação das palavras ou porque se tornam incompreensiveis para o vulgo ignorante.

Para substituir esse dígrafo, Soares Barbosa (1822, p. 70-71) aponta o uso de $<$ c $>$ antes de $<$ a $>$ e de $<$ qu $>$ antes de $<$ i $>$.

Não usamos ja de $\mathrm{CH}$ aspirado pelas razões, que apontei no principio do Capitulo. Em lugar delle pomos $C$ simples antes de a, escrevendo Arcanjo, Monarca; e $Q U$ antes de $i$, escrevendo Arquitecto, Monarquia, e não Archanjo, Monarcha, Architecto, Monarchia, como antes se escrevia.

Apesar dessas reflexões do gramático, na GPLP vamos encontrar ainda a utilização da grafia $<\mathrm{ch}>$ para representar o som [k], nomeadamente nas palavras Christo, Chrysippo, echo, epochas, eschola, inchoativa, mechanico, patriarcha, psychologicas. Na GL, são também vários os exemplos que ilustram o uso desse dígrafo, a saber: Archanjo, Archeologia, christã, chronica, Chronologico, Eucharistia, Parochial, Parocho, Patriarcha.

No entanto, na GPLP verifica-se que essa grafia convive com a outra, como demonstra a ocorrência dos pares eschola / escola, mechanico / mecanicos, exemplos que surgem na GL grafados apenas com <c/qu>, a par de muitos outros, como os que se seguem Arquiduque, Arquiduques, Arquiduqueza, Arquiduquezas, coro, escola, escóla, escolas, escólas, escolastica, Monarca, Monarcas, monarquia, Monarquias, Monarquica, Monarquico, quimera, quimerica, quimericos.

Relativamente ao dígrafo <ph>, Feijó (1781, p. 61) refere:

[...] na Orthografia das palavras Gregas, que saõ nomes proprios, naõ se mude $o \mathrm{Ph}$ em $\mathrm{F}$, para as naõ fazermos improprias, e tirar-lhes o distinctivo de que sã̃ Gregas. Nas appellativas, quem usar de $\mathrm{Ph}$, escreverá sem erro, e por analogia; quem escrever com F, fará a palavra Grega aportuguezada; e naõ deixará de escrever bem; porque sempre fica a mesma pronunciaçaõ.

Nesse sentido, verificamos que admite a grafia com $<\mathrm{ph}>$ e também $\operatorname{com}<\mathrm{f}\rangle$, como são claros os exemplos Euphrates e Orthografia.

Para Soares Barbosa (1822, p. 70), esse é usado para representar o $\langle\varphi\rangle$ grego e, segundo o autor, de todos, esse é o dígrafo que o uso mais tem substituído.

Das consoantes Gregas aspiradas, a que o uso está mais propenso a largar da nossa Orthographia he o PH, que elle sem rebuço ja escreve com F em Filosofia, Fysica, Metafysica, Profeta, Triumfo, e podia escrever da mesma maneira Antiphona, Aphorismo, Blasphemo, Phantasma, Philippe, Camphora, Diphthongo, Phebo, Phaetonte, Alphabeto \&c.

As palavras do gramático refletem uma certa flexibilidade, pois refere que usualmente já se escrevem várias palavras $\operatorname{com}<\mathrm{f}>$ em substituição do $<\mathrm{ph}>\mathrm{e}$ ainda se podiam escrever mais. Dessa ocorrência dá-nos também conta Lima (1736, p. 90): "Quanto a PH naõ usa tanto de Aspiraçaõ; e muitas vezes escreve: Anfiteatro, Blasfemia, Filippe, Filosofo, Proféta, Triunfo".

No tocante à ocorrência desse digrafo, verificamos que na GL ele surge apenas nas seguintes palavras: Calligraphia, Cosmographia, Ephemerides, Geographia, Philantropo, Philippe, Philippeville, Philosophia, Phylantropicos, Physiologicas, 
Raphael, Sophocles, Tipographia. Na GPLP, ocorre em palavras como anastrophes, bucephalo, cacophonia, diphthongo, elephante, orthographia, paragraphos, phenomenos, phrases ${ }^{15}$, entre outras.

Fizemos, ainda, uma pesquisa na GPLP pelos exemplos que o gramático apresenta como usualmente escritos com $<\mathrm{f}>$ (filosofia, fysica, metafysica, profeta, triumfo) e todos eles, com exceção de triumfo, do qual não há mais nenhuma ocorrência, se encontram grafados em outros passos com <ph> (philosophia, physica, metaphysica, propheta), o que reforça a ideia de variação existente.

Esse fenómeno também é visivel na GL, como comprovam os seguintes exemplos: Geographia / Geografia, geografica, Geograficas, Geografico, Geograficos; Philippe / Filippe; Raphael / Rafael; Tipographia / Typografia, typograficos. No entanto, apesar dessa oscilação, verifica-se que há uma preferência pela forma grafada com $<\mathrm{f}>$, como fica claro se atentarmos nos exemplos que se seguem e no seu número de ocorrências: Philosophia (1) / filosofia (20), filosofica (2), filosoficamente (1), filosoficas (4), Filosofico (1), Filosoficos (1), filosofos (5).

Essa variação verifica-se igualmente com o digrafo <th>, para o qual Soares Barbosa (1822, p. 70) diz encontrar palavras em que se usa e em que se elimina.

$\mathrm{Na} G P L P, \mathrm{o}<\mathrm{th}>$ surge nas palavras Athenas, author ${ }^{16}$, authorizado, epenthese, labirintho, methodo, orthoepia, parenthese, pathetico, theoria, thesouro, entre outras; na GL, a lista é bastante extensa, seguindo-se alguns exemplos: authentico, author, authoridade, Catharina, cathecismo, Catholica, Mathematica, theatro, Theologia, thermometro, Thesouro.

Das palavras que Soares Barbosa apresenta como exemplos de formas que alguns usam sem <th>, temos ocorrências, nos textos, de Catharina e catholica, que surgem representadas com o digrafo. $\mathrm{Na} G L$, ainda que fique clara a preferência pelo <th>, encontramos alguns exemplos que são reveladores da oscilação que era comum na época: autorizado / authorizado, destronar/ desthronar, Jacinto / Jacintho, Metafisicos / methafisicas, Rhetorica / Rhethorica.

Dos quatro dígrafos, resta apenas o $<\mathrm{rh}>$, usado para representar o $<\mathrm{r}>$ que no grego tem espírito áspero. Quando faz referência aos diferentes contextos em que ocorre a letra <r>, Feijó não apresenta esse dígrafo, porém na terceira parte da sua Orthographia elenca algumas palavras que se escrevem com $<\mathrm{rh}>$.

Por sua vez, Soares Barbosa (1822, p. 70) salienta que esse é raro em grego e muito mais em português: "O RH aspirado he mais raro nas palavras Gregas, e muito mais nas poucas, que com elle passárão ao Portuguez como Rhetorica e não Rethorica, como alguns escrevem, Rheumatismo, Catarrho, que ja muitos escrevem Reumatismo, Catarro".

Assim, para além dos exemplos já apresentados na citação, na GPLP apenas encontramos mais três palavras grafadas com <rh>: arrhas, pyrrhonicos e rhythmo, não se registando qualquer variação.

Quanto às ocorrências deste digrafo na $G L$, estas também comprovam o seu parco uso, surgindo apenas nas palavras rheumatico, Rhetorica, Rhethorica, Rheno, Rhodes.

Passemos, de seguida, à sistematização dos usos destes grupos nos textos. 
Quadro 3 - O uso do $<\mathrm{h}>$ nos dígrafos gregos na $G L$ e na GPLP

\begin{tabular}{|l|l|}
\hline & GL e GPLP \\
\hline Dígrafo $<\mathrm{ch}>$ & $\begin{array}{l}\text { Christo, Chrysippo, echo, epochas, inchoativa, mechanico, patriarcha, } \\
\text { psychologicas, Archanjo, Archeologia, christã, chronica, Chronologico, } \\
\text { Eucharistia, Parochial, Patriarcha }\end{array}$ \\
\hline Dígrafo $<\mathrm{ph}>$ & $\begin{array}{l}\text { anastrophes, bucephalo, cacophonia, diphthongo, elephante, } \\
\text { metaphysica, orthographia, paragraphos, phenomenos, philosophia, } \\
\text { phrases, Calligraphia, Cosmographia, Ephemerides, Geographia, } \\
\text { Philantropo, Philippe, Philippeville, Philosophia, Phylantropicos, } \\
\text { Physiologicas, Raphael, Sophocles, Tipographia }\end{array}$ \\
\hline Dígrafo $<\mathrm{th}>$ & $\begin{array}{l}\text { Athenas, author, authorizado, Catharina, diphthongo, epenthese, } \\
\text { labirintho, methodo, orthoepia, parenthese, pathetico, theoria, thesouro, } \\
\text { authentico, authoridade, cathecismo, Catholica, Mathematica, theatro, } \\
\text { Theologia, thermometro }\end{array}$ \\
\hline Dígrafo $<\mathrm{rh}>$ & $\begin{array}{l}\text { arrhas, pyrrhonicos, rhythmo, rheumatico, Rhetorica, Rhethorica, Rheno, } \\
\text { Rhodes }\end{array}$ \\
\hline
\end{tabular}

Fonte: Elaborado pelas autoras.

\section{CONSIDERAÇÕES FINAIS}

Em suma, no que respeita à grafia do ditongo [aj], podemos concluir que, nos dois textos, ele assume a forma <ae> sempre que se trata de formas do plural das palavras terminadas em <-al>; na conjugação dos verbos nas segundas pessoas do plural, verifica-se que o uso da grafia <ai> é maioritário, contudo não existe uniformidade. Quanto à grafia <ay>, na $G L$ esta surge associada maioritariamente a topónimos e antropónimos. Na GPLP, podemos considerar que essa grafia foi apenas apresentada para referir a possibilidade do seu uso na época, não encontrando porém qualquer representatividade ao longo do texto.

No que concerne ao $<\mathrm{h}>$, quer na $G L$, quer na $G P L P$, ele é usado enquanto sinal de aspiração e sinal distintivo, marca etimológica, função anti-hiática e elemento constitutivo dos digrafos portugueses $<\mathrm{ch}, \mathrm{h}$, nh $>$ e dos digrafos gregos $<$ ch, ph, th, rh>. Relativamente a esses últimos, verificamos que, apesar de muitas palavras já se escreverem com $<\mathrm{c}$, qu, f, t, r $>$, o que se constata é que os digrafos que representam as consoantes aspiradas gregas ainda se mantêm nos dois textos.

Tendo em conta os cotejos estabelecidos entre a Gazeta de Lisboa e a Grammatica philosophica, conseguimos identificar marcas ortográficas próprias da época estudada, verificando-se, contudo, uma constante oscilação de grafias, fruto do cruzamento do sistema etimológico com o sistema da pronunciação.

\section{Orthographyc issues in the Gazeta de Lisboa (1815) and IN the Grammatica PHILOSOPHICA DA LINGUA PORTUGUEZA (1822)}

Abstract: In this article, based on a corpus consisting of the Gazeta de Lisboa (1815) and the Grammatica philosophica da lingua portugueza (1822), two different text types, a journalistic text and a grammar, we intend to reflect on some 
orthographic issues that characterized the early nineteenth century, since the reading of the texts allowed us to confirm the existence of a clear orthographic instability. Therefore, we will consider some examples that precisely demonstrate this inconstancy, particularly as regards the use of the diphthong [aj] and $<\mathrm{h}>$.

Keywords: Gazeta de Lisboa (1815). Grammatica philosophica da lingua portugueza (1822). Orthography.

\section{REFERÊNCIAS}

BARBOSA, J. S. Grammatica philosophica da lingua portugueza ou Principios da grammatica geral applicados á nossa linguagem. Lisboa: Na Typographia da Academia das Sciencias, 1822.

BARBOSA, J. S. Gramática filosófica da lingua portuguesa (1822). Edição anastática, comentário e notas críticas de Amadeu Torres. Braga: Publicações da Faculdade de Filosofia, Universidade Católica Portuguesa, 2005.

BELO, A. As gazetas e os livros. A Gazeta de Lisboa e a vulgarização do impresso em Portugal (1715-1760). Lisboa: Imprensa de Ciências Sociais, 2001.

FEIJÓ, J. de M. M. Orthographia, ou arte de escrever, e pronunciar com acerto a lingua portugueza para uso do excellentissimo duque de Lafoens. Lisboa Occidental: Na Officina de Miguel Rodrigues, 1734.

FEIJÓ, J. de M. M. Orthographia, ou arte de escrever, e pronunciar com acerto a lingua portugueza para uso do excellentissimo duque de Lafoens. Lisboa: na Regia Officina Typografica, 1781.

GAZETA DE LISBOA. Gazeta de Lisboa, ano 1815. Lisboa: Na Impressão Regia, 1815.

GONÇALVES, M. F. As ideias ortográficas em Portugal. De Madureira Feijó a Gonçalves Viana (1734-1911). Braga: Fundação Calouste Gulbenkian, 2003.

LIMA, L. C. de. Orthographia da lingua portugueza. Lisboa Occidental: Na Officina de Antonio Isidoro da Fonseca, 1736.

TENGARRINHA, J. História da imprensa periódica portuguesa. 2. ed. rev. e ampl. Lisboa: Caminho, 1989.

VERNEY, L. A. Verdadeiro metodo de estudar. Tomo Primeiro. Valensa: Na oficina de Antonio Balle, 1746.

VIEIRA, C. A. de F. Ensaio sobre a orthographia portugueza. Porto: Typographia Commercial, 1844.

Recebido em abril de 2014. Aprovado em outubro de 2014. 